\title{
Study of high mobility carriers in Ni-doped CdO films
}

\author{
A A DAKHEL \\ Department of Physics, College of Science, University of Bahrain, P.O. Box 32038, Bahrain, Kingdom of Bahrain
}

MS received 23 December 2011; revised 16 March 2012

\begin{abstract}
Cadmium oxide (CdO) doped with different amounts of nickel ion thin films have been prepared on silicon and glass substrates by vacuum evaporation technique. The effects of nickel doping on the structural, electrical, optical and optoelectronic properties of the host $\mathrm{CdO}$ films were systematically studied. The sample elemental composition was determined by the $\mathrm{X}$-ray fluorescence spectroscopy method. The $\mathrm{X}$-ray diffraction method was used to study the crystalline structure of the samples. It shows that some of $\mathrm{Ni}^{3+}$ ions occupy mainly locations when in interstitial positions and $\mathrm{Cd}^{2+}$-ion vacancies of $\mathrm{CdO}$ lattice. The bandgap of Ni-doped $\mathrm{CdO}$ suffers narrowing till 10-12\% compared to undoped $\mathrm{CdO}$. Such bandgap narrowing was studied within the framework of the available models. The electrical behaviours show that all the prepared Ni-doped $\mathrm{CdO}$ films are degenerate semiconductors. However, the nickel doping influences all the optoelectrical properties of CdO. Their d.c. conductivity, carrier concentration and mobility increased compared to undoped CdO film. The largest mobility of $112 \cdot 6 \mathrm{~cm}^{2} / \mathrm{V} \cdot \mathrm{s}$ was measured for 1-2\% Ni-doped $\mathrm{CdO}$ film. From optoelectronics point of view, Ni-doped $\mathrm{CdO}$ can be used in infrared-transparent-conducting-oxide (NIR-TCO) applications.
\end{abstract}

Keywords. Cadmium-nickel oxide; Ni-doped CdO; CdO.

\section{Introduction}

Investigations on cadmium oxide $(\mathrm{CdO})$ produce a wide range of applications in optoelectronic area like transparent conducting oxide (TCO) as well as other type of applications like gas sensors (Lewis and Paine 2000; Yan et al 2001; Zhao et al 2002). These applications stand on its optoelectronic properties. It is known that nonstoichiometry of $\mathrm{CdO}$ caused by cadmium interstitials and/or oxygen vacancies generates $n$-type semiconducting behaviour with a resistivity of $10^{-2}$ $10^{-4} \Omega \cdot \mathrm{cm}$. Moreover, CdO films are transparent especially in the NIR spectral region with a direct bandgap of 2.2$2.7 \mathrm{eV}$ (Chopra and Ranjan 1993; Carballeda-Galicia et al 2000; Zhao et al 2002). CdO crystallizes in a cubic structure of lattice constant $0.4695 \mathrm{~nm}$ and space group Fm $3 \mathrm{~m}$ of 6-coordination (JCPDS 05-840).

It was found that it is possible to engineer the optoelectronic properties of $\mathrm{CdO}$ by doping with different metallic ions such as In, Y (Dou et al 1998), Tl (Dakhel 2008), Al (Gupta et al 2009), Sc (Shu et al 2004), Fe (Dakhel 2010a, b,c), Sm (Dakhel 2009a), Dy (Dakhel 2009b), etc. It was observed that when the size of the dopant ion is slightly smaller than that of $\mathrm{Cd}^{2+}$ ion, then the conduction determinants (conductivity $(\sigma)$, mobility $\left(\mu_{\mathrm{el}}\right)$ and carrier concentration $\left.\left(N_{\mathrm{el}}\right)\right)$ of the host $\mathrm{CdO}$ are improved and the lattice unit cell compresses. However, doping of $\mathrm{CdO}$ with ions of much smaller ionic radius like boron (Dakhel 2011a,b; Yakuphanoglu 2011a) still require investigation, although such doping was carried out for other TCOs like

$\overline{\text { (adakhil@sci.uob.bh) }}$
$\mathrm{ZnO}, \mathrm{SnO}_{2}, \mathrm{In}_{2} \mathrm{O}_{3}$ and $\mathrm{NiO}$ (Morales and Sanchez 1999; Hanamoto et al 2001; Lou et al 2009; Gao et al 2011). Nickel was selected in the present work. The 6-coordination $(\mathrm{CN}=6)$ ionic radius of $\mathrm{Ni}^{3+}$ is $0.056 \mathrm{~nm}$, which is much smaller than that of $\mathrm{Cd}^{2+}$ ion, $0.095 \mathrm{~nm}$ (Shannon 1976). The effect of nickel doping on the structural, electrical and optical properties of the host $\mathrm{CdO}$ is reported. It will be seen that nickel doping of $\mathrm{CdO}$ is efficient for obtaining high mobility in comparison to other dopants and could be successfully used in optoelectronic applications based on its IR-TCO characteristics. Doping of $\mathrm{CdO}$ with $\mathrm{Ni}$ still has not been well investigated, however Ni-doped $\mathrm{CdO}$ films prepared by sol-gel method was studied by Yakuphanoglu (2011b).

\section{Experimental}

$\mathrm{CdO}$ thin films incorporated with different amounts of nickel ions were grown on glass substrates. Silicon wafer substrates were also used only for X-ray fluorescence study. The starting materials were pure $\mathrm{NiCl}_{2}$ and $\mathrm{CdO}$ (from Fisher Sci. Company/USA and Fluka A.G./Germany, respectively). The starting materials were evaporated alternatively (layer-bylayer) by alumina baskets (Midwest tungsten Service, USA). The glass slide substrates were ultrasonically cleaned and silicon wafers were chemically (using HF) cleaned before inserting in a vacuum chamber. The as-grown films were totally oxidized and stabilized by flash annealing in air at $400{ }^{\circ} \mathrm{C}$ for $1 \mathrm{~h}$ keeping them inside the closed furnace for slow natural cooling to room temperature. All samples were prepared in almost the same conditions including reference pure 
$\mathrm{CdO}$ and $\mathrm{NiO}$ films. The evaporated masses were controlled during preparation with a piezoelectric microbalance crystal sensor of a Philips FTM5 thickness monitor fixed close to the substrate. The thicknesses were measured after annealing by an MP100-M spectrometer (Mission Peak Optics Inc., USA), to be $0 \cdot 10-0 \cdot 15 \mu \mathrm{m}$. The weight ratio of Ni content to $\mathrm{Cd}$ in each film was measured with $\mathrm{X}$-ray fluorescence (XRF) method by utilizing an X-ray beam obtained from a Cu-anode of Philips tube (Philips PW-1710) operated at $15 \mathrm{kV} / 5 \mathrm{~mA}$ and a sensitive Amptek XR-100CR detector of energy resolution $180 \mathrm{eV}$ at $5.9 \mathrm{keV}$. The measured relative content of $\mathrm{Ni}$ to $\mathrm{Cd}$ in the studied samples were 0.6 , $1 \cdot 2,2 \cdot 0,3 \cdot 4,4 \cdot 6,9 \cdot 4,12 \cdot 0$ and $15.5 \%$ (wt) (accordingly, the samples were named $0.6 \% \mathrm{Ni}$, for example). The structure of the prepared films was studied with X-ray diffraction (XRD) method by using a Philips PW1710 $\theta-2 \theta$ system of $\mathrm{CuK}_{\alpha}$ radiation $(\lambda=0.15406 \mathrm{~nm})$, in a $2 \theta$ range of $10-70^{\circ}$ and a step size of $0 \cdot 02^{\circ}$. The spectral optical transmittance $(T(\lambda))$ were measured at normal incidence in UV-VIS-NIR spectral region (300-3000 $\mathrm{nm}$ ) by a Shimadzu UV-3600 double beam spectrophotometer. The electrical measurements were carried out with a standard Van-der-Pauw method with aluminum dot contacts in a magnetic field of about $1 \mathrm{~T}$ and using a Keithley 195A digital multimeter and a Keithley 225 current source.

\section{Results and discussion}

\subsection{Structural characterization}

Figure 1 shows energy-dispersion X-ray fluorescence spectrum for one of the prepared thin Ni-doped $\mathrm{CdO}$ film on silicon substrate. The spectrum shows Cd L-band (3.133$3.53 \mathrm{keV})$ and $\mathrm{NiK}_{\alpha}$-band $(7.47 \mathrm{keV})$ in addition to some signals from the source. The signals of $\mathrm{NiK}_{\alpha}$ and $\mathrm{CuK}_{\alpha}$

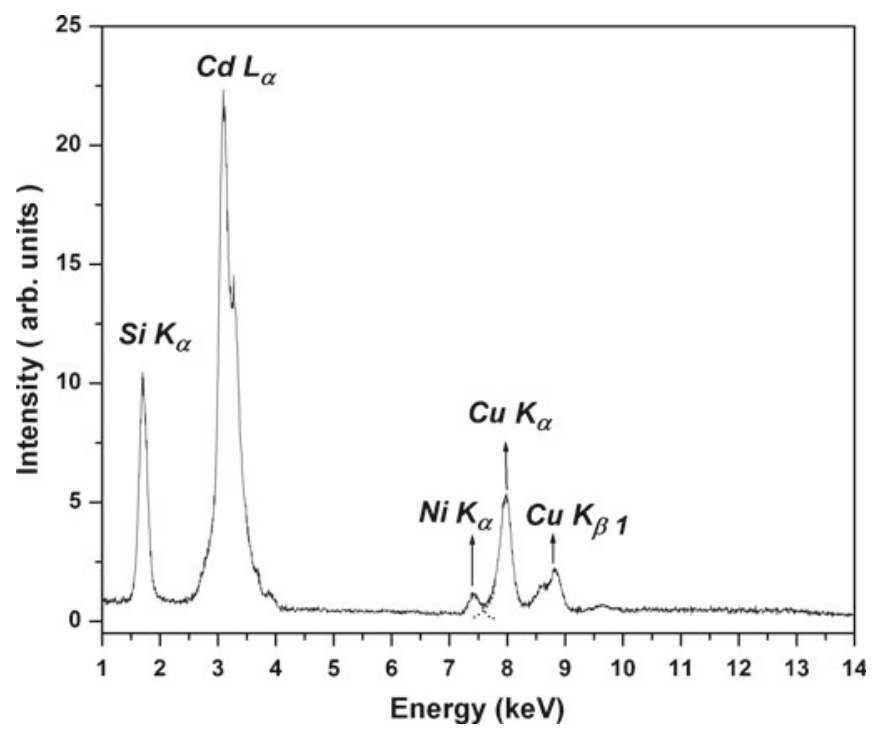

Figure 1. X-ray fluorescence of Ni-incorporated $\mathrm{CdO}$ films grown on silicon substrate. are partially overlapped due to the limited resolution of the detector. The overlapping was deconvoluted with a computer program. The relative fraction ratio of $\mathrm{Ni}$ to $\mathrm{Cd}$ in film samples were determined by measuring the ratio of integral intensity of $\mathrm{NiK}_{\alpha}$-band to that of $\mathrm{Cd} \mathrm{L}$-band and using the known method of micro-radiographic analysis. The reference samples were pure $\mathrm{CdO}$ and $\mathrm{NiO}$ thin films.

Figure 2 shows X-ray diffraction (XRD) patterns of the prepared undoped and $\mathrm{Ni}$-doped $\mathrm{CdO}$ films grown on glass substrates. These patterns reveal that all the investigated films are polycrystalline with a cubic $\mathrm{F} m 3 m \mathrm{CdO}$ structure, as given by JCPDS $05-640$. Any $\mathrm{Ni}$ oxide or $\mathrm{Cd}-\mathrm{Ni}$ oxide reflection was not detected in the XRD pattern due to the incorporation of $\mathrm{Ni}$ ions in the lattice of $\mathrm{CdO}$ and absence of any compound formed in the films. The films grown on glass substrate have [111] energetically preferred orientation growth, which is the usual growth of $\mathrm{CdO}$ films prepared by different techniques. The mean X-ray crystallite size (CS) was estimated from the most intensive (111) reflection by using Scherrer equation (Kaelble 1967): $C S=0.9 \lambda / \beta \cos \theta$, where $\lambda$ is the X-ray wavelength, $\beta$ the full width at half maximum (FWHM) of the (111) peak (in radian) and $\theta$ the Bragg angle of the considered (111) reflection. The variation of $\mathrm{CS}$ with $\mathrm{Ni} \%$ incorporation level is shown in figure 3; the crystallites grew gradually with increasing $\mathrm{Ni}$ incorporation to almost a saturation.

The exact lattice parameter and hence the unit cell volume $\left(v_{\text {cell }}\right)$ of the host $\mathrm{CdO}$ film structure grown on glass substrate is calculated by a least squares method and the results are given in figure 4 . The unit cell volume is reduced with increasing $\mathrm{Ni}$ incorporation attaining a stable value. Figure 4 can be considered as a scale of evaluation of the trend of the actual doping process of nickel into $\mathrm{CdO}$ lattice. Hence, $\mathrm{Ni}$ doping in host $\mathrm{CdO}$ lattice increases with increasing $\% \mathrm{Ni}$ incorporation till $\sim 10-12 \%$, after which the

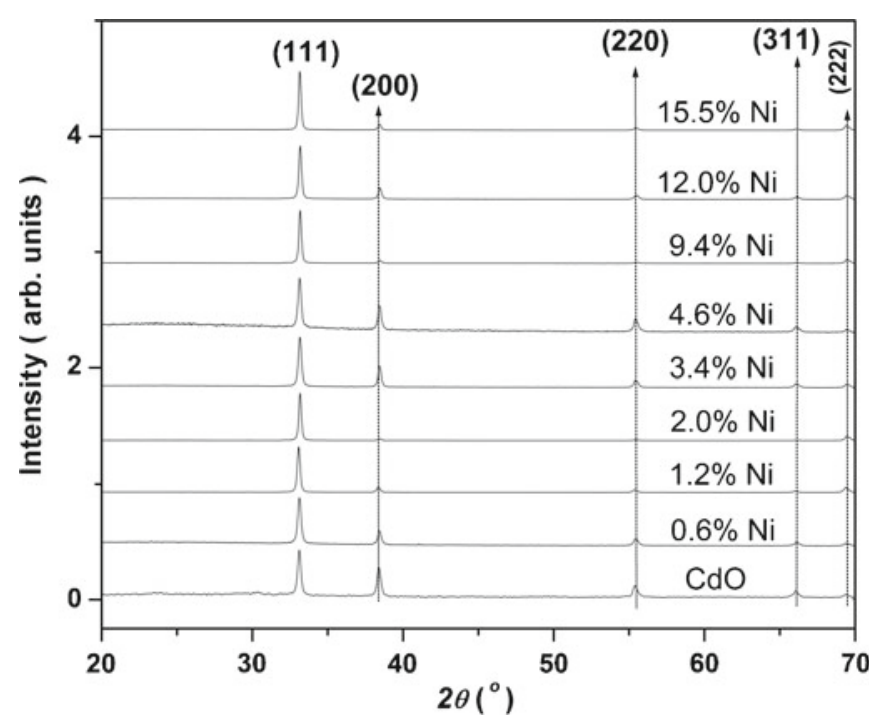

Figure 2. X-ray diffraction patterns for undoped and Ni-doped $\mathrm{CdO}$ films deposited on glass substrates. 


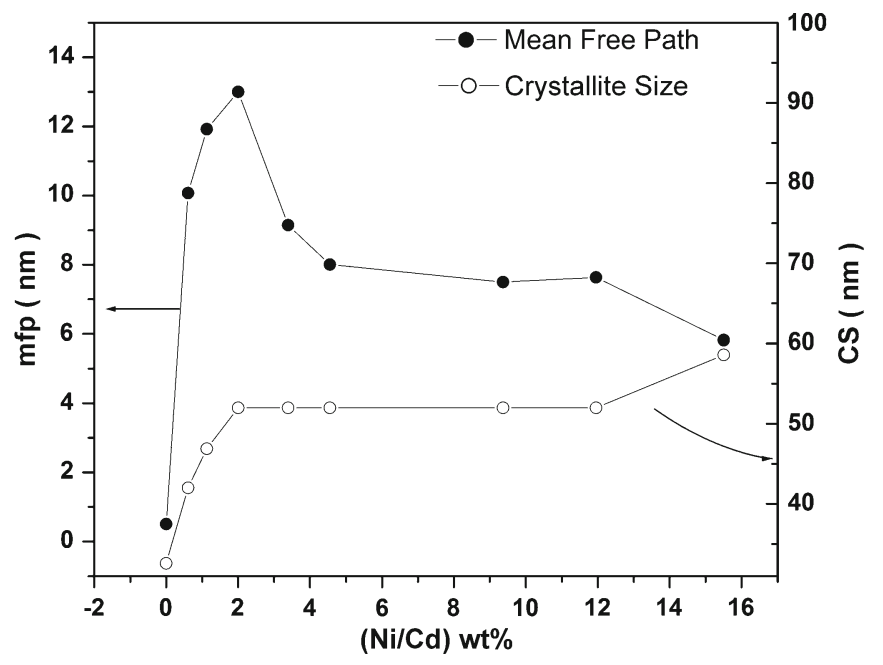

Figure 3. Dependence of mean free path $(\mathrm{mfp})$ and crystallite size (CS) on Ni doping level.

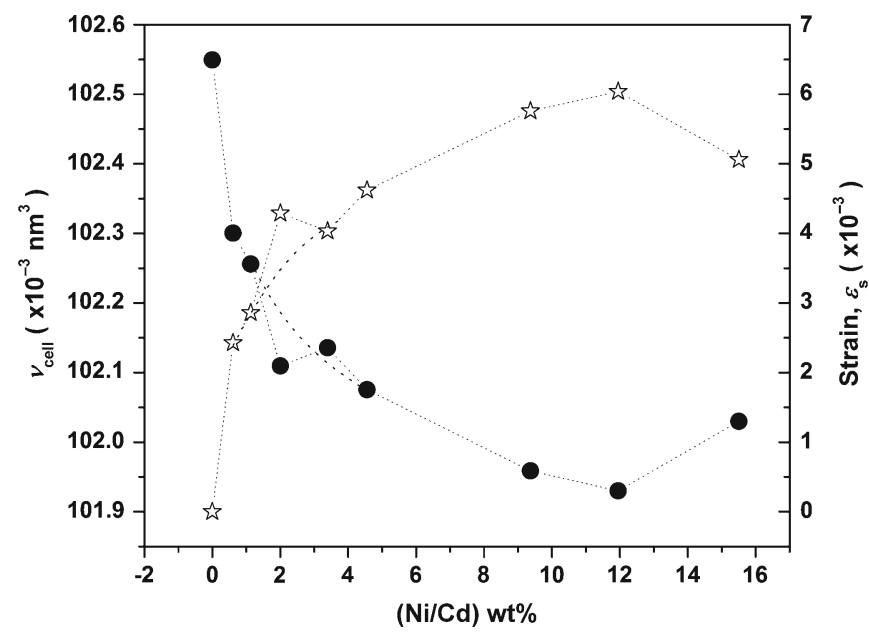

Figure 4. Variation of unit cell volume $\left(v_{\text {cell }}\right)$ and structural strain $\left(\varepsilon_{\mathrm{S}}\right)$ with doping level of $\mathrm{Ni}$-doped $\mathrm{CdO}$ films grown on glass substrates.

incorporated $\mathrm{Ni}$ begins to accumulate on the crystallite boundaries. The decrease of the unit cell volume of the host $\mathrm{CdO}$ lattice due to Ni-doping can be explained as follows. Nickel ions have smaller size than that of $\mathrm{Cd}^{2+}$ and thus they have high diffusivity with low activation energy. The dissolution of $\mathrm{Ni}$ ions in $\mathrm{CdO}$ lattice can be realized by substitution for $\mathrm{Cd}^{2+}$ ions and occupying of locations in interstitial positions. However, $\mathrm{Ni}^{3+}$ substitution for $\mathrm{Cd}^{2+}$ ions is unlikely according to Hume-Rothery (HR) rules. According to (HR) rules, the substitutional solid solution of nickel oxide and cadmium oxides unlikely occurs since the radii of the host $\mathrm{Cd}^{2+}$ and substituted $\mathrm{Ni}^{3+}$ ions are different by about $41 \%$ (more than $15 \%$ ). In addition, the ions have different valencies although both ions have almost similar electronegativities (1.8 and 1.7 Pau for $\mathrm{Ni}$ and $\mathrm{Cd}$, respectively) and both oxides ( $\mathrm{NiO}$ and $\mathrm{CdO}$ ) have cubic structure. In the result, the HR conditions do not fully fulfilled so that they do not prefer to form substitutional solid solution. This result is also confirmed when applying modified HR rules (Sood 1978) in which the constitutional alloys will be formed if the implanted species have atomic radius less than that of host radius by no more than $15 \%$ and the electronegativity within \pm 0.7 of that of the host atoms. Therefore, occupation of locations in interstitial positions of $\mathrm{CdO}$ lattice with $\mathrm{Ni}^{3+}\left(\mathrm{Ni}_{i}^{i^{\bullet \bullet}}\right)$ ions is more likely to happen. Such occupation disturbs the charge neutrality of the unit cell that can be settled by the creation of $\mathrm{Cd}^{2+}$ ion vacancies $\left(V_{\mathrm{Cd} \cdot} \cdot\right)$ that reduces $v_{\text {cell }}$ or by leaving some of $\mathrm{Cd}^{2+}$ ions in their positions that also would reduce $v_{\text {cell }} . \mathrm{Ni}^{3+}$ ions that occupy interstitial positions might move with thermal motion, small size and high diffusivity and occupy $\mathrm{Cd}^{2+}$-ion vacancies $\left(V_{\mathrm{Cd} \cdot \bullet}\right)$. In Kroger-Vink notations, the defect reaction is

$$
\mathrm{NiO} \stackrel{\mathrm{CdO}}{\longrightarrow} V_{\mathrm{Cd}}^{\mathrm{x}} \bullet+e^{\prime}+\mathrm{Ni}_{i}^{\bullet \bullet \bullet},
$$

where $V_{\mathrm{Cd}}^{\mathrm{x}} \bullet$ is the $\mathrm{Cd}^{2+}$-vacancy of neutral charge, $\mathrm{Ni}_{i}^{\bullet \bullet \bullet}$ the nickel ion occupied interstitial position with triple positive charge, and $e^{\prime}$ an electron (a site is not normally specified).

The change in unit cell volume of Ni-doped $\mathrm{CdO}\left(\Delta v_{\text {cell }}\right)$ compared to that of pure $\mathrm{CdO}\left(v_{\text {cell }}^{\mathrm{o}}\right)$ can be used to calculate the structural strain: $\varepsilon_{\mathrm{s}}=\Delta v_{\text {cell }} / v_{\text {cell }}^{\mathrm{o}}$; the results are shown in figure 4 of the order $-10^{-3}$. The negative sign of $\varepsilon_{\mathrm{s}}$ refers to a compressive nature of the stress $\left(\sigma_{\mathrm{st}}\right)$ that can be estimated to be around $0.2 \mathrm{GPa}$ by $\sigma_{\mathrm{st}}=\varepsilon_{\mathrm{s}} B$, where $B$ is the average bulk modulus of $\mathrm{CdO}, 158 \mathrm{GPa}$ (Liu et al 2004). However, the created stress is far to be capable of creating a crystalstructural transformation, it can only produce a decrease in the unit cell.

\subsection{D.C. electrical properties}

The room temperature electrical-conduction determinants of $\mathrm{Ni}$-doped $\mathrm{CdO}$ films grown on glass substrate were measured with a standard Van der Pauw method and the average results are presented in table 1 and figure 5. The experimental error due to the contact spot size was estimated to be about 5\%. The electrical measurements show that all Ni-doped $\mathrm{CdO}$ films behave as $n$-type semiconductors. The obtained results of electrical-conduction determinants for the undoped $\mathrm{CdO}$ film agree with the earlier published data (Zhao et al 2002). In general, the results show that light doping ( $\sim 2 \%)$ of $\mathrm{CdO}$ film with $\mathrm{Ni}$ ions strongly improves all its electrical-conduction determinants. The resistivity of the host $\mathrm{CdO}$ film decreases with Ni-doping from $10^{-2}$ to $10^{-4} \Omega \cdot \mathrm{cm}$ and attain a minimum value $\left(\sim 3 \cdot 1 \times 10^{-4} \Omega \cdot \mathrm{cm}\right)$ at $1-2 \%$ Ni. For higher doping level (more than $2 \%$ ), the resistivity slightly increases due to an accumulation of some of $\mathrm{Ni}$ ions (or amorphous $\mathrm{Ni}$ oxide) on the crystallite boundaries. It is clear that a significant accumulation of amorphous $\mathrm{Ni}$ oxide takes place in the sample $10.5 \% \mathrm{Ni}$. The important finding in the present measurements is the high values of mobility $\left(\sim 120 \mathrm{~cm}^{2} / \mathrm{V} \cdot \mathrm{s}\right)$ especially at light doping level of $\sim 1-2 \%$. It is important to mention for comparison that such high mobility was also observed in $\mathrm{CdO}$ doped with $\mathrm{Al}^{3+}$ 
Table 1. Measured electrical conduction determinants [resistivity $(\rho)$, mobility $\left(\mu_{\mathrm{el}}\right)$ and carrier concentration $\left.\left(N_{\mathrm{el}}\right)\right]$ and bandgaps $\left(E_{\mathrm{g}}\right)$ for undoped and Ni-doped CdO films grown on glass substrate.

\begin{tabular}{|c|c|c|c|c|}
\hline Sample & $\rho\left(\times 10^{-4} \Omega \cdot \mathrm{cm}\right)$ & $\mu_{\mathrm{el}}\left(\mathrm{cm}^{2} / \mathrm{V} \cdot \mathrm{s}\right)$ & $N_{\mathrm{el}}\left(10^{20} \mathrm{~cm}^{-3}\right)$ & $E_{\mathrm{g}}(\mathrm{eV})$ \\
\hline $\mathrm{CdO}$ & 201 & 7.03 & 0.44 & $2 \cdot 1$ \\
\hline $0.6 \% \mathrm{Ni}$ & $5 \cdot 2$ & $100 \cdot 5$ & $1 \cdot 2$ & $2 \cdot 3$ \\
\hline $1.2 \% \mathrm{Ni}$ & $3 \cdot 25$ & $80 \cdot 0$ & $2 \cdot 4$ & $2 \cdot 1$ \\
\hline $2.0 \% \mathrm{Ni}$ & $3 \cdot 1$ & $112 \cdot 6$ & $1 \cdot 8$ & $2 \cdot 2$ \\
\hline $3.4 \% \mathrm{Ni}$ & 4.62 & $81 \cdot 2$ & 1.7 & $2 \cdot 1$ \\
\hline $4.6 \% \mathrm{Ni}$ & $5 \cdot 17$ & $71 \cdot 1$ & 1.7 & $2 \cdot 3$ \\
\hline $9.4 \% \mathrm{Ni}$ & 4.63 & $61 \cdot 0$ & $2 \cdot 2$ & $2 \cdot 2$ \\
\hline $12.0 \% \mathrm{Ni}$ & $4 \cdot 27$ & $59 \cdot 6$ & $2 \cdot 5$ & 1.9 \\
\hline $15.5 \% \mathrm{Ni}$ & $4 \cdot 6$ & $54 \cdot 6$ & $3 \cdot 0$ & $1 \cdot 8$ \\
\hline
\end{tabular}

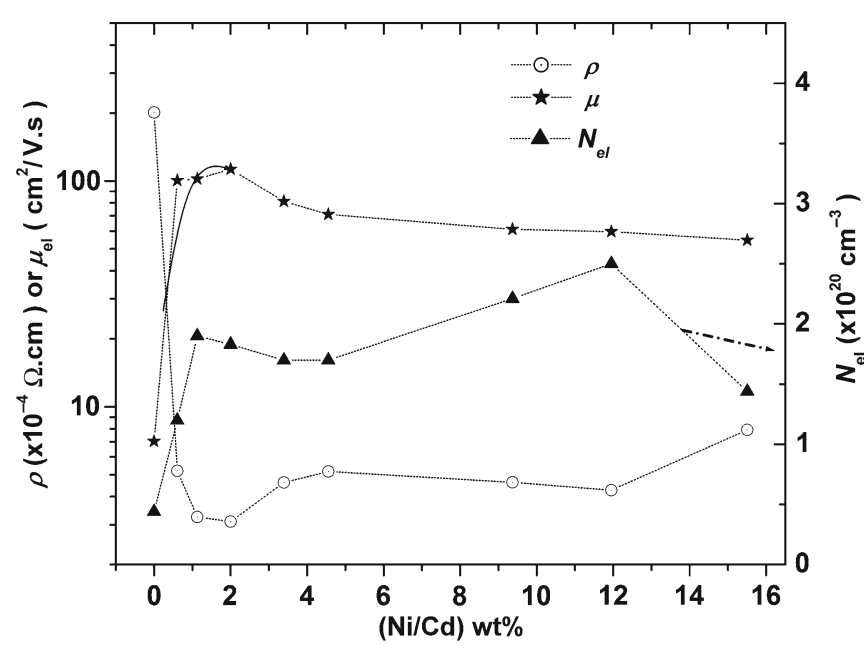

Figure 5. Variation of resistivity $(\rho)$, mobility $\left(\mu_{\mathrm{el}}\right)$ and carrier concentration $\left(N_{\mathrm{el}}\right)$ with doping level of $\mathrm{Ni}$-doped $\mathrm{CdO}$ films grown on glass substrates.

(Saha et al 2007) (Notice that ion $\mathrm{Al}^{3+}$ has 6-coordination radius of $0.0535 \mathrm{~nm}$ (Shannon 1976) which is also much less than that of $\mathrm{Cd}^{2+}$ ). These results can be explained as a consequence of $\mathrm{Ni}^{3+}$ ion doping by occupation interstitial sites in $\mathrm{CdO}$ lattice $\left(\mathrm{Ni}_{i}^{\bullet \bullet \bullet}\right)$ due to its smaller ion radius and high mobility; such explanation was also adopted for B-doped CdO (Carballeda-Galicia et al 2000; Dakhel 2011a,b). As mentioned above, due to the charge-balance rule, the formation of $\mathrm{Ni}_{i}^{\cdot \bullet \bullet}$ should be accompanied with the creation of $\mathrm{Cd}^{2+}$ vacancies. Furthermore, the formation of $\mathrm{Ni}_{i}^{\bullet \bullet \bullet}$ ions provides more conduction electrons. Thus, Nidoping creates donors that improve the conduction determinants and induces band evolution, which merges with the conduction band and reduces the bandgap, as will be seen later.

The mean free path (mfp) of conduction electrons can be estimated by the following equation (Minami et al 1995):

$$
\ell_{\mathrm{mfp}}=(h / 2 e)\left(3 N_{\mathrm{el}} / \pi\right)^{1 / 3} \mu_{\mathrm{el}},
$$

which gives 6-13 $\mathrm{nm}$, as shown in figure 3. The mfp increases rapidly attaining the utmost value $(13 \mathrm{~nm})$ in $2.0 \% \mathrm{Ni}$

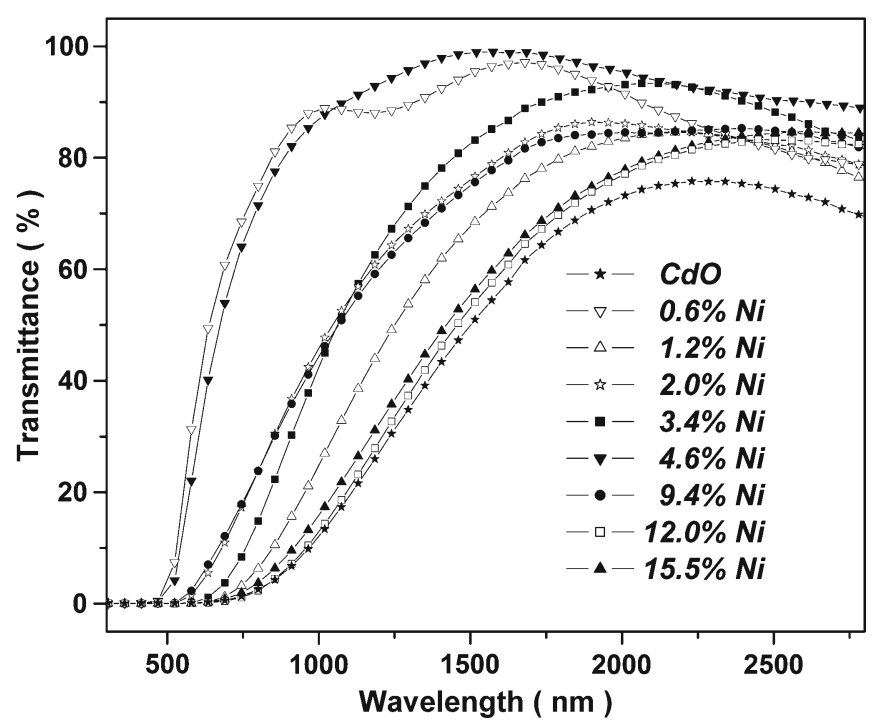

Figure 6. Optical transmittance of undoped and Ni-doped $\mathrm{CdO}$ films grown on glass substrates.

sample, then it decreases rapidly attaining almost stable value. Thus, the mfp values for all the samples are far less than CS (figure 3), which means that the grain or crystallite boundary scattering of the carriers has low contribution in reducing the mobility of free carriers in the films. Thus other types of carrier scattering like lattice and impurity scattering plays a main role (this point will also be confirmed later in § 3.4).

\subsection{Optoelectronic properties}

The experimentally corrected normal transmittance $T(\lambda)$ of the prepared $\mathrm{Ni}$-doped $\mathrm{CdO}$ films grown on corning glass substrate in the UV-VIS-NIR region $(300-3000 \mathrm{~nm})$ are presented in figure 6 . It is clear that the maxima $\left(\lambda_{\mathrm{m}}\right)$ of the transmittance $T(\lambda)$ spectra are being in the NIR region. The high wavelength side of the transmittance curves $T(\lambda)$ of the doped $\mathrm{CdO}$ samples shows a clear damping down due to the high density of free electrons (Minami et al 1995). The spectral absorption coefficient $\alpha(\lambda)$ is related to the absorbance 
$A(\lambda)$ by $A(\lambda)=\alpha(\lambda) d$, where $d$ is the film thickness. The optical bandgap $E_{\mathrm{g}}$ is evaluated according to the known energy-exponential relation (Tauc and Abeles 1969):

$$
A E=B_{\text {op }}\left(E-E_{\mathrm{g}}\right)^{m},
$$

where $B_{\mathrm{op}}$ is the film's constant and the exponent $m$ is equal to 0.5 or 2 for direct or indirect transitions, respectively. Thus, the extrapolation of the plot of $(A E)^{2}$ vs $E$ for any sample, as shown in figure 7 gives the values of its direct bandgap (table 1). Figure 8 shows graphically the variation of $E_{\mathrm{g}}$ with Ni-doping level. Thus, the bandgap of $\mathrm{CdO}$ slowly decreases with $\mathrm{Ni}$-doping. It was observed that the narrowing of $\mathrm{CdO}$ bandgap, due to Ni-doping, is accompanied with increasing carrier concentration. Such observation is in contrast with the known Moss-Burstein (B-M) effect or bandgap widening (BGW) (Pankove 1975).

Doping of host $\mathrm{CdO}$ with $\mathrm{Ni}$ ions can cause two simultaneous phenomena, bandgap narrowing (BGN) and bandgap widening $(\mathrm{BGW})$. BGN may be physically attributed to the change in electron-host ions interaction in addition to introducing electron-ionized doped impurity interaction. These interactions generate impurity conduction-band tail broadening that finally leads to emergence of the impurity band with the conduction band causing effectively BGN (Zhang et al 2008). Therefore, it is necessary to correlate the bandgap $\left(E_{\mathrm{g}}\right)$ variations with the carrier concentration by considering both BGW and BGN effects. BGW is given by (Pankove 1975):

$$
\mathrm{BGW}=S_{\mathrm{BGW}} N_{\mathrm{el}}^{2 / 3},
$$

where $S_{\mathrm{BGW}}^{\mathrm{th}}=1.348 \times 10^{-18} \mathrm{eV} \cdot \mathrm{m}^{2} . \mathrm{BGN}$ is given by:

$$
\mathrm{BGN}=\left(S_{\mathrm{BGN}}^{(1)} N_{\mathrm{el}}^{2 / 3}+S_{\mathrm{BGN}}^{(2)} N_{\mathrm{el}}^{1 / 3}\right),
$$

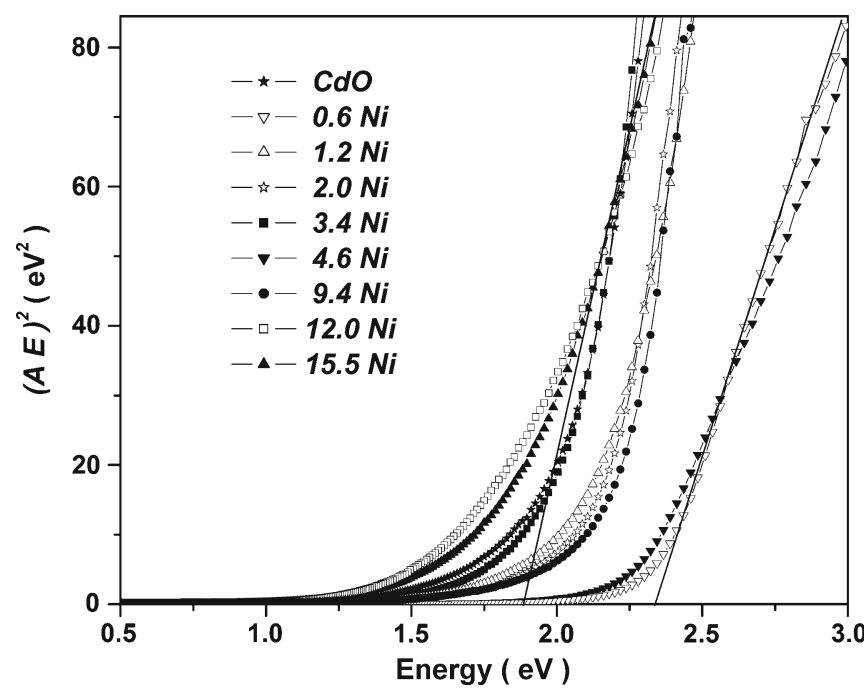

Figure 7. Calculated (points) energy dependence of spectral optical absorbance $(A)$ in Tauc plot for undoped and Ni-doped CdO. Lines determine direct bandgaps. where $S_{\mathrm{BGN}}^{(1)}=4.49 \times 10^{-19} \mathrm{eV} \cdot \mathrm{m}^{2}$ and $S_{\mathrm{BGN}}^{(2)}=2.836 \times$ $10^{-9} / \varepsilon_{\mathrm{r}}$ (Dakhel 2010a,b, 2011b). The effective dielectric constant, $\varepsilon_{\mathrm{r}}$, can be considered as $\varepsilon_{\mathrm{r}}=\alpha \varepsilon_{\infty}$, where $\alpha$ is the film's parameter that might come from the non-parabolic band effects and $\varepsilon_{\infty}$ the long-wavelength dielectric constant that is equal to $\varepsilon_{\infty}=n^{2}=1.6^{2}$ for pure $\mathrm{CdO}$. Thus:

$$
\begin{aligned}
\Delta E_{\mathrm{g}}= & E_{\mathrm{g}}-E_{\mathrm{g} 0}=\mathrm{BGW}-\mathrm{BGN}=S_{\mathrm{BGW}, \mathrm{BGN}} N_{\mathrm{el}}^{2 / 3} \\
& -S_{\mathrm{BGN}}^{(2)} N_{\mathrm{el}}^{1 / 3}+C_{\mathrm{f}},
\end{aligned}
$$

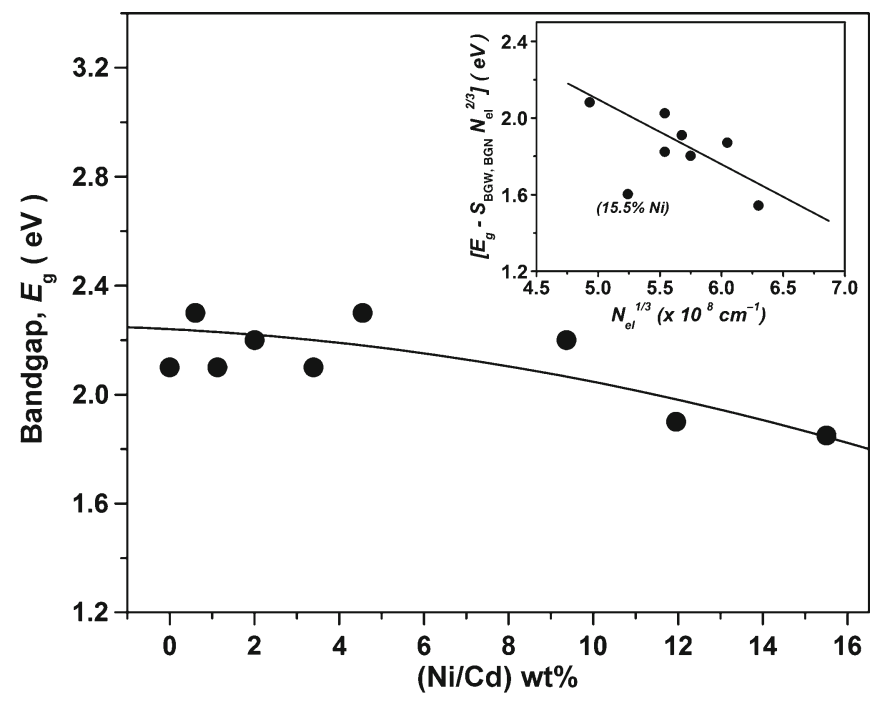

Figure 8. Variation of bandgap $\left(E_{\mathrm{g}}\right)$ with doping level of $\mathrm{Ni}$ doped $\mathrm{CdO}$ films. Inset shows dependence of optoelectronic function $\left(E_{\mathrm{g}}-S_{\mathrm{BGW}, \mathrm{BGN}} N_{\mathrm{el}}^{2 / 3}\right)$ on carrier concentration, $N_{\mathrm{el}}^{1 / 3}$. Straight line represents best fit according to (2).

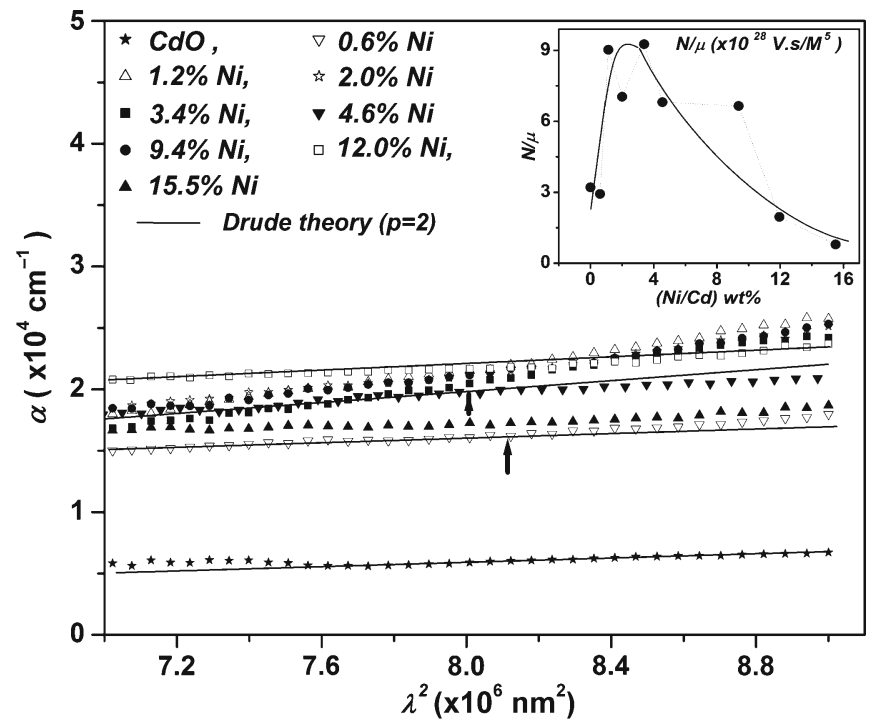

Figure 9. Dependence of absorption coefficient, $\alpha$ on $\lambda^{2}$ in NIR spectral region for undoped and $\mathrm{Ni}$-doped $\mathrm{CdO}$ films. Inset shows dependence of $\left(N_{\mathrm{el}} / \mu\right)$ ratio measured optically on doping level of Ni-doped $\mathrm{CdO}$ films. 
where $C_{\mathrm{f}}$ is a fitting parameter and $S_{\mathrm{BGW}, \mathrm{BGN}}=S_{\mathrm{BGW}}-$ $S_{\mathrm{BGN}}^{(1)}=8.98 \times 10^{-19} \mathrm{eV} \cdot \mathrm{m}^{2}$. Straight line was obtained by plotting $\left[E_{\mathrm{g}}-S_{\mathrm{BGW}, \mathrm{BGN}} N_{\mathrm{el}}^{2 / 3}\right]$ vs $N_{\mathrm{el}}^{1 / 3}$, as shown in the inset of figure 9 , with $S_{\mathrm{BGN}}^{(2)}=3.38 \times 10^{-9} \mathrm{eV} \cdot \mathrm{m}$, thus $\alpha=0.32$. The experimental and theoretical orders of magnitudes for $S_{\mathrm{BGN}}^{(2)}$ are identical. The inset of figure 9 shows that the sample 15.5\% $\mathrm{Ni}$ is different from other samples (as for all the results), which is attributed to the significant accumulation of amorphous nickel oxide on the crystallite or grain boundaries.

\subsection{NIR absorption properties}

For wavelengths larger than the threshold of absorption region at NIR $\sim 2500 \mathrm{~nm}\left(\lambda>\lambda_{\mathrm{m}}\right)$, the absorption is mainly caused by the free carriers (Qiao et al 2006), which can be studied in the framework of classical Drude theory (Mergel and Qiao 2002). Thus, $\alpha=A_{\mathrm{op}} \lambda^{2}$ and $A_{\mathrm{op}}=\left(5.243 \times 10^{-13}\right)\left(1 / n \gamma^{2}\right)\left(N_{\mathrm{el}} / \mu_{\mathrm{el}}\right)_{\mathrm{op}} \quad($ Qiao et al 2006; Dakhel 2010c), where $A_{\text {op }}$ is the film's parameter and $n$ the refractive index at NIR region $(n=1 \cdot 6)$. The reduced effective mass of electron, $m_{\mathrm{e}}^{*}=\gamma m_{\mathrm{e}}$, where $m_{\mathrm{e}}$ is the freeelectron mass and $\gamma=0.274$ for $\mathrm{CdO}$ (Asahi et al 2001), and $\left(N_{\mathrm{el}} / \mu_{\mathrm{el}}\right)_{\mathrm{op}}$ is the ratio of density to mobility of electrons as measured by optical method. By neglecting small variations of $n$ in NIR, a linear relationship $\alpha$ vs $\lambda^{2}$ should be observed, as shown in figure 10 . Thus, it is possible to estimate the ratio $(N / \mu)_{\text {op }}$ and the results are shown in the inset of figure 9. The ratio $\left(N_{\mathrm{el}} / \mu_{\mathrm{el}}\right)_{\mathrm{op}}$ has the utmost value for around $2 \% \mathrm{Ni}$ doping level.

From other side it is generally known that in the NIR spectral region, $\alpha \sim \lambda^{p}$, where $p$ varies from 1.5 to 3.5 depending on the dominant carrier scattering mechanism in the sample in a certain wavelength range. Consequently, for scattering of conduction electrons by acoustic-phonons scattering $p \approx 1 \cdot 5$, by optical phonons $p \approx 2-2 \cdot 5$, and by ionized impurities $p \approx 3-3.5$ (Asahi et al 2001; Singh and Mehra 2001). In the present work, the value $p=2$ is valid almost for the whole studied NIR wavelength range, which means that the electron-optical phonon scattering is the significant scattering of conduction electrons in the NIR spectral region in pure and Ni-incorporated $\mathrm{CdO}$. However, it was observed that for samples $12 \% \mathrm{Ni}$ and $15.5 \% \mathrm{Ni}$, there is an inclination from the relation $\alpha \sim \lambda^{2}$ for $\lambda \gtrsim 1840 \mathrm{~nm}$, which indicates that the scattering by ions have a considerable contribution for such high Ni impurity ions.

\section{Conclusions}

The structural, optical, d.c.-electrical and optoelectronic properties of nickel-doped $\mathrm{CdO}$ films grown on glass substrates were investigated. The structure and electrical studies show that dopant $\mathrm{Ni}^{3+}$ ions mostly occupied locations in interstitial positions and $\mathrm{Cd}^{2+}$-ion vacancies in $\mathrm{CdO}$ lattice. It was observed that doping with $\mathrm{Ni}^{3+}$ ions slightly shrinks the bandgap by about $10 \%$ and compresses the host $\mathrm{CdO}$ unit cell by $0 \cdot 2-0.6 \%$ compared to undoped $\mathrm{CdO}$. The bandgap narrowing was analysed according to available models. All the prepared $\mathrm{Ni}$-doped $\mathrm{CdO}$ films show degenerate semiconducting behaviour. However, the electrical-conduction determinants were improved with nickel light doping. The utmost improvement of conduction parameter takes place with samples $1-2 \% \mathrm{Ni}$, where the conductivity increases by about 62 times, mobility by about 12 times and electronic concentration by about 5 times compared to pure $\mathrm{CdO}$ film prepared by the same method. Only the improvement of mobility can emulate doping with other metals like boron of much smaller ionic volume than $\mathrm{Cd}^{2+}$, for example. We emphasize here that on the largest mobility of $112.6 \mathrm{~cm}^{2} / \mathrm{V} \cdot \mathrm{s}$ measured for $1-2 \% \mathrm{Ni}$-doped $\mathrm{CdO}$ film. From optoelectronics point of view, Ni-doped $\mathrm{CdO}$ can be used in infrared-transparentconducting-oxide (NIR-TCO) applications in addition to the magnetic properties that should appear with $\mathrm{Ni}$ doping.

\section{References}

Asahi R et al 2001 Proceeding of the Int. symposium on transparent oxide thin films for electronics and optics. Tokyo, Japan

Carballeda-Galicia D M, Castanedo-Perez R, Jimenez-Sandoval O, Jimenez-Sandoval S, Torres-Delgado G and Zuniga-Romero C I 2000 Thin Solid Films 371105

Chopra K L and Ranjan S 1993 Thin film solar cells (NY: Plenum Press)

Dakhel A A 2008 Phys. Status Solidi (a) 2052704

Dakhel A A 2009a J. Alloys Compds. 47551

Dakhel A A 2009b Solar Energy 83934

Dakhel A A 2009c Mater. Chem. Phys. 117284

Dakhel A A 2010a Thin Solid Films 5181712

Dakhel A A 2010b J. Alloys Compds. 5047

Dakhel A A 2010c Solar Energy 841433

Dakhel A A 2011a J. Mater. Sci. 466925

Dakhel A A 2011b Curr. Appl. Phys. 1111

Dou Y, Egdell R G, Walker T, Law D S L and Beamson G 1998 Surf. Sci. 398241

Gao L, Zhang Y, Zhang J-M and Xu K-W 2011 Appl. Surf. Sci. 257 2498

Gupta R K, Ghosh K, Patel R, Mishra S R and Kahol P K 2009 Curr. Appl. Phys. 9673

Hanamoto K, Sasaki M, Miyatani K, Kaito C, Miki H and Nakayama Y 2001 Nucl. Instrum. Meth. Phys. Res. B173 287

Kaelble E F (ed.) 1967 Handbook of X-rays for diffraction, emission, absorption and microscopy (New York: McGraw-Hill) p. 17

Lewis B J and Paine D C 2000 Mater. Res. Soc. Bull. 2522

Liu H, Mao H K, Somayazulu M, Ding Y, Meng Y and Hausermann D 2004 Phys. Rev. B70 094110

Lou X, Zhao X and He X 2009 Solar Energy 832103

Mergel D and Qiao Z 2002 J. Phys. D: Appl. Phys. 35794

Minami T, Takata S, Sato H and Sonohara H 1995 J. Vac. Sci. Technol. A13 1095

Morales J and Sanchez L 1999 Solid State Ionics 126219

Pankove J I 1975 Optical processes in semiconductors (NY: Dover) p. 36

Powder Diffraction File, Joint Committee for Powder Diffraction Studies (JCPDS) file no. 05-0640 
Qiao Z, Agashe C and Mergel D 2006 Thin Solid Films 496520

Saha B, Das S and Chattopadhyay K K 2007 Sol. Energ. Mat. Sol. C. 911692

Shannon R D 1976 Acta Crystallogr. A32 751

Shu S, Yang Y, Medvedova J E, Ireland J R, Metz A W, Ni J, Kannewurf C R, Freeman A J and Tobin T J 2004 J. Am. Chem. Soc. 12613787

Singh A V and Mehra R M 2001 J. Appl. Phys. 905661

Sood D K 1978 Phys. Lett. A68 469

Tauc J and Abeles F (eds) 1969 Optical properties of solids (The Netherlands: North Holland)
Walukiewicz W 1990 Phys. Rev. B41 10218

Xu C, Bai L and Giles N C 2006 J. Phys.: Condens. Matter 182741

Yakuphanoglu F 2011a Solar Energy 852704

Yakuphanoglu F 2011b J. Sol-Gel Sci. Technol. 59569

Yan M, Lane M, Kannewurf C R and Chang R P H 2001 Appl. Phys. Lett. 7802342

Zhang Y Z, Lu J G, Ye Z Z, He H P, Zhu L P, Zhao B H and Wang L 2008 Appl. Surf. Sci. 2541993

Zhao Z, Morel D L and Ferekides C S 2002 Thin Solid Films 413203 